\title{
A Hawaiian limpet facilitates recruitment of a competitively dominant invasive barnacle
}

\author{
Chela J. Zabin ${ }^{1,2, *}$, Andrew Altieri ${ }^{1,3}$ \\ ${ }^{1}$ Department of Zoology and Ecology, Evolution and Conservation Biology Program, University of Hawaii at Manoa, \\ 2538 McCarthy Mall, Edmondson Hall, Honolulu, Hawaii 96822, USA \\ ${ }^{2}$ Present address: Smithsonian Environmental Research Center, Romberg Tiburon Center for Environmental Studies, \\ 3152 Paradise Drive, Tiburon, California 94920, USA \\ ${ }^{3}$ Present address: Marine Science Center, Northeastern University, 430 Nahant Rd., Nahant, Massachusetts 01908, USA
}

\begin{abstract}
At an intertidal site on the island of Oahu, Hawaii, the abundance of the invasive barnacle Chthamalus proteus was negatively correlated with abundance of the native limpet Siphonaria normalis. As the substratum at this site was a conglomerate of materials, we hypothesized that the observed pattern was the result of differences in substratum preferences, and/or negative interactions between the 2 species, or both. We used manipulative field experiments to test these hypotheses, and then generalized our findings with surveys across several sites that differed in substratum type and abundances of barnacles and limpets. The limpet recruited in highest numbers to light-colored substrata. The barnacle settled in highest numbers on rough substrata, with a trend toward higher settlement on dark-colored substrata. Surprisingly, in experimental plots, recruitment of the barnacle was positively correlated with the density of the limpet. In contrast, limpet densities increased in experimental plots from which barnacles had been removed. Thus the pattern at this site appears to result from a combination of substratum preferences and interactions between the 2 species. These experiments and surveys of other intertidal sites on Oahu suggest that (1) limpets and barnacles have little effect on each other at low densities, (2) at higher densities limpets facilitate settlement of barnacles, but barnacles have a negative effect on limpets, and (3) substratum type can mediate the density-dependent interactions between these 2 species by affecting their settlement patterns.
\end{abstract}

KEY WORDS: Impacts of invasion - Facilitation $\cdot$ Competition $\cdot$ Chthamalus proteus $\cdot$ Siphonaria normalis $\cdot$ Barnacle-limpet interactions $\cdot$ Biological invasions $\cdot$ Intertidal zone

\section{INTRODUCTION}

Biological invasions are a threat to marine systems worldwide (Carlton 1999, Grosholz 2002). The primary goals of invasion biology include the ability to predict how a non-native species entering a new ecosystem will interact with resident species and how characteristics of native species can affect the invasibility of an ecosystem. From a conservation standpoint, the ability to predict impacts on native species is particularly important. At this point in the development of invasion biology, it is not clear whether lessons learned from natural ecological communities can be applied to accurately predict interactions between native and non-native species.
Until the recent invasion of Chthamalus proteus, a barnacle native to the Caribbean Sea and the western Atlantic, the Hawaiian archipelago was generally without high cover of intertidal barnacles. The native barnacles Nesochthamalus intertextus, Euraphia hemblei and Tessoropora pacifica are generally restricted to cracks and crevices in areas of moderate to high wave exposure, with cover rarely exceeding $40 \%$ in the barnacle zone (authors' unpubl. data). C. proteus arrived in the Hawaiian Islands between 1973 and 1993 (Southward et al. 1998) and has since spread around the island of Oahu, becoming highly abundant, particularly in low-energy (i.e. less wave-exposed) environments. In Kaneohe Bay, on the island's windward 
side, cover of $C$. proteus can extend from the high to low intertidal zone and reach nearly 100\% (authors' unpubl. data). Throughout Hawaii, the barnacle coexists with the native pulmonate limpet Siphonaria normalis, which is frequently the most abundant native organism in the barnacle zone. The propensity of $C$. proteus to settle in high numbers and on protected shorelines presents a novel situation for $S$. normalis, which would have rarely encountered native barnacles in these habitats or in such abundance.

Barnacles and limpets interact strongly in many intertidal ecosystems, often with effects that reverberate throughout the community. Barnacles may have negative impacts on limpets. Dense patches of barnacles attract predators that also prey on limpets (Creese 1982); barnacles can inhibit limpets from grazing effectively (e.g. Branch 1976, Choat 1977, Sutherland \& Ortega 1986, Hodgson 1999), and barnacles may limit the ability of limpets to maintain firm attachment to the substratum (Hawkins \& Hartnoll 1982). Limpets can have negative effects on barnacle densities by 'bulldozing', crushing, or ingestion as they graze over a substratum (e.g. Stimson 1970, Miller \& Carefoot 1989, Iwasaki 1993a,b). On the other hand, positive interactions have also been recorded. By removing algae from rock, limpets can facilitate barnacle settlement and survival (Iwasaki 1993b), and because barnacles create a rugose surface, they can increase the survival of small limpets by providing them with protection from desiccation, heat stress, and the grazing activities of larger limpets and predators (Lewis \& Bowman 1975, Branch 1976, Choat 1977, Creese 1982, Hawkins \& Hartnoll 1982).

Interactions between Chthamalus proteus and limpets in the barnacle's native range have not been studied, nor have interactions between intertidal barnacles and limpets been previously investigated in Hawaii. If strong interactions are occurring between C. proteus and Siphonaria normalis, the results of these interactions could affect the success of the invasive barnacle and limit the distribution and abundance of the native limpet. In fact, a striking small-scale distribution pattern can be seen on a seawall on Coconut Island (Moku O Loe) in Kaneohe Bay, where both species are highly abundant. S. normalis is present in much higher abundance on light-colored limestone rocks, whereas $C$. proteus is more abundant on dark-colored igneous rocks at the same tidal height and shoreline aspect (authors' pers. obs.).

Substratum selectivity by settlers and differential survival across micro-habitats are factors influencing the abundance and distribution of barnacles (e.g. Edmondson \& Ingram 1939, Crisp \& Barnes 1954, Chabot \& Bourget 1988, Raimondi 1988). While selectively at settlement might play a part in limpet distribution, adult limpets also migrate to more suitable micro-habitats after settlement (e.g. Vermeij 1971a, Levings \& Garrity 1984, Branch et al. 1990, Hodgson 1999). Substratum effects, pre- or post-settlement, rather than interspecific interactions could provide an alternate explanation for the observed distribution pattern of the native limpet and invasive barnacle in Hawaii. Finally, the distribution pattern could be the result of the combined effects of substratum and barnacle-limpet interactions.

In this study, we used a combination of field surveys and manipulative experiments to quantify the abiotic (substratum) and biotic (interactions with native limpet) factors that may have contributed to the successful invasion of Chthamalus proteus, and to examine whether the invasive barnacle is affecting the native limpet Siphonaria normalis.

\section{MATERIALS AND METHODS}

Study organisms and sites. Chthamalus proteus is an intertidal barnacle, typically $6 \mathrm{~mm}$ in rostro-carinal length, native to the Gulf of Mexico, the Caribbean Sea and the tropical/sub-tropical western Atlantic Ocean (Dando \& Southward 1980). It was not found in a survey of Oahu's intertidal barnacles in the early 1970s (Matsuda 1973), and was first collected-but misidentified as a native barnacle - in Pearl Harbor in 1993 (J. Brock pers. comm.). By the time the identity of $C$. proteus was discovered, it had already become widespread. It is now present on most of the main Hawaiian Islands, and occurs elsewhere in the tropical Pacific, including Guam, Midway, the Marianas and the Society Islands (Southward et al. 1998, and A. J. Southward pers. comm.). The barnacle most likely arrived in the Hawaiian Islands on vessel hulls and is continuing to spread in this manner (S. Godwin pers. comm.).

The limpet Siphonaria normalis occurs in the mid- to upper rocky intertidal zone in both calm and waveexposed sites. It has a widespread distribution throughout the Indo-Pacific (Kay 1979) and disperses via crawl-away juveniles hatched from egg masses ( $M$. G. Hadfield pers. comm). The limpet can reach a maximum length of $17 \mathrm{~mm}$, but is typically less than $10 \mathrm{~mm}$ in Hawaii, particularly in sheltered locations (pers. obs.). The diet of $S$. normalis is not known, but as a group, siphonariids generally consume macroalgae (e.g. Enteromorpha spp. and Ulva spp.), diatoms, and algal sporelings (Creese \& Underwood 1982, Hodgson 1999). S. normalis grazes while the substratum is awash during rising or falling tides, and returns to a home scar between foraging bouts (Cook 1969, Cook \& Cook 1978). 
Experiments were conducted at the Hawaiian Institute for Marine Biology (University of Hawaii) on Coconut Island in the southern portion of Kaneohe Bay on the western shore of the Hawaiian Island of Oahu $\left(21^{\circ} 26^{\prime} \mathrm{N}, 157^{\circ} 47^{\prime} \mathrm{W}\right)$. Protected by a barrier reef, Kaneohe Bay is a low wave-energy environment. Intertidal assemblages in the bay are typical of waveprotected areas in Hawaii. Experiments were conducted on a series of cement blocks on the northwestern side of the island and on or near the seawall mentioned in the 'Introduction', which is on the south side of the island. These areas were chosen for experiments because they provided uniform surfaces which allowed for attachment of experimental units, eliminated varying habitat complexity as a confounding factor, and standardized orientation. The seawall abuts a sandy reef flat and rises to $\sim 1.5 \mathrm{~m}$ above mean lower low water (MLLW). It consists of a mixture of concrete, old limestone rock and basalt. The series of blocks runs perpendicular to the shore over a shallow reef flat. The tops of the blocks are about $10 \mathrm{~cm}$ above MLLW. The surface of the material is homogeneous.

Experimental results were generalized through a series of surveys conducted at 3 additional sites: 2 southfacing shores, Kuhio Beach in Waikiki $\left(21^{\circ} 27^{\prime} \mathrm{N}\right.$, $\left.157^{\circ} 80^{\prime} \mathrm{W}\right)$ and Diamond Head Beach Park (21 $26^{\prime} \mathrm{N}$, $\left.157^{\circ} 80^{\prime} \mathrm{W}\right)$, and one site at the northern edge of Kaneohe Bay, Kualoa Beach Park (21 $31^{\prime}$ N, $157^{\circ} 49^{\prime}$ W). At Waikiki and Kualoa, surveys were made on the shoreward side of concrete seawalls and at Diamond Head on one limestone and one basaltic segment of an intertidal rock platform. The Kualoa site is protected from all but the largest winter waves by a barrier reef. An offshore reef crest protects Waikiki and Diamond Head from the full brunt of oceanic waves, but both sites experience seasonally high waves compared to Kualoa and Coconut Island.

Coconut Island seawall survey. To determine the relative contributions of the color and rugosity of substratum and the presence of the other organism in the current distribution of barnacles and limpets on the Coconut Island seawall, we counted individuals of Chthamalus proteus and Siphonaria normalis in 52 randomly placed quadrats along a $50 \mathrm{~m}$ transect line at approximately $18 \mathrm{~cm}$ above MLLW. We used small quadrats $(7.5 \times 5 \mathrm{~cm})$ because of the extremely high density of organisms. We noted the color (dark versus light) of the substratum and its rugosity (rough versus smooth). Substratum was recorded as 'light' if its color value was equal to or lighter than fresh cement. Anything darker was considered 'dark'. The substratum was recorded as 'rough' if it contained pits or projecting gravel $>10 \mathrm{~mm}$ in the dimension perpendicular to the wall, otherwise it was considered 'smooth'. The effects of the number of $S$. normalis, substratum color, substratum texture, and interactions between all factors on the abundance of $C$. proteus were tested using ANCOVA. The effects of the number of C. proteus and substratum color and texture on the abundance of $S$. normalis were examined similarly. To meet assumptions of normality, counts of barnacles and limpets were $\log$-transformed $\left(\log _{10}+1\right)$.

Recruitment preferences. To test for substratum preferences in the recruitment of Siphonaria normalis and Chthamalus proteus, we created 4 types of tiles: dark rough, dark smooth, light rough, and light smooth. The tiles were made using Quikrete cement mix (gravel was removed from the mix by sifting it through a screen with $5 \mathrm{~mm}$ mesh openings) poured into $6.5 \times 5 \mathrm{~cm}$ rectangular plastic molds to a height of $2 \mathrm{~cm}$. Dark colored tiles were created by adding Quikrete black cement dye and basalt sand to the cement mixture. Coral sand was added to the cement to make light-colored tiles. To create rough tiles, we used a wooden tongue depressor to make a single line approximately $10 \mathrm{~mm}$ wide down the center of each tile from top to bottom and another from side to side before the cement hardened. This increased surface complexity by creating a groove of $\sim 10 \mathrm{~mm}$ depth with edges that projected above the plane of the tile by about 5-10 mm. The tiles were attached randomly onto 3 cinderblocks using Velcro strips in 3 rows of 8 tiles. This configuration allowed the small tiles to completely cover the surface of the cinderblocks. The cinderblocks were placed side by side, forming a continuous surface in front of the seawall, with the tiles in a horizontal orientation at $\sim 18 \mathrm{~cm}$ above MLLW level. These were left in place from May to September 2002. At the end of that study period, we counted S. normalis and C. proteus on each tile during a low tide. The effects of tile color and rugosity on the number of limpet and barnacle recruits were analyzed for each species using ANCOVA, with the other species used as a covariate to account for any interspecific effects on recruitment. All data were log transformed as above.

Effects of Siphonaria normalis on recruitment of Chthamalus proteus. Cages: To examine the effects of adult Siphonaria normalis on recruitment of Chthamalus proteus across types of substrata, we quantified barnacle recruitment to tiles with and without adult limpets. We constructed 8 replicates of the 4 tile types described above, except that tiles were $11 \times 10 \mathrm{~cm}$, and rough tiles had 2 lines, rather than one, running in each direction. Plastic mesh fencing ( $3 \mathrm{~mm}$ mesh size) $5 \mathrm{~cm}$ high was attached around the edges of each tile, and plastic turf was placed around the outside of the fences with marine epoxy (Splash Zone Z-Spar) to restrict movement of limpets between tiles and surrounding areas. One tile of each type was placed on a cinderblock, for a total of 8 cinderblocks and 32 tiles. 
The order of tile placement was random on each cinderblock. The cinderblocks were placed in front of the seawall. Four were designated as limpet-addition treatments (32 limpets added to each tile to match ambient density on the nearby wall) and 4 blocks as no-limpet treatments (no limpets added, and incidental migrants removed periodically). The cinderblocks were arranged in 4 limpet-addition and no-limpet pairs along the seawall; the order of treatment type within each pair was random. To reduce sediment accumulation on tiles, the cinderblocks were placed on their sides after 2 weeks so that the tiles had a vertical orientation. The experiment ran from May to August 2003 during which time limpet densities were maintained with additions and removal on a bi-weekly basis. Since a number of individuals of $S$. normalis migrated or recruited onto tiles of both types of treatments, and some limpets were lost from a pair of cinderblocks during a storm, we used the number of limpets on the tiles at the end of the experiment as a covariate in an ANCOVA rather than using limpet treatment type as a categorical factor. Tile color and rugosity were considered fixed factors and cinderblock pair (as a block effect) was a random factor in the analysis. Data were transformed as above to meet assumptions of normality.

Barriers: A second experiment examining the effects of Siphonaria normalis on recruitment of Chthamalus proteus was conducted to account for the possible shading and flow effects of the mesh fences in the previous experiment. Four segments of the seawall, all $50 \mathrm{~cm}$ in width, and running from the bottom to the top of the $S$. normalis zone (1 $\mathrm{m}$ vertical height) were used as experimental areas, because they provided a standardized surface amenable to removal of limpets. This portion of the seawall was made of a single material (smooth concrete); thus the effect of limpets on barnacle density was examined in isolation from the effect of substratum type. Each segment was divided in half, one side of which was randomly designated as a control plot and the other as a treatment plot. A strip of plastic turf $4 \mathrm{~cm}$ wide was attached with marine epoxy to the seawall to prevent limpet migration between plots and to delimit the edges of each plot. All limpets $>2 \mathrm{~mm}$ in size were removed by hand from the treatment plots bi-weekly from August 2003 to June 2004 (tiny limpets $<2 \mathrm{~mm}$ in size could not be removed without major alteration of the substratum). We counted barnacles in five $4 \times 4 \mathrm{~cm}$ randomly placed quadrats within the middle of the barnacle zone of each plot. Despite barriers and the hand-picking, limpets were still present on the removal plots, and in some cases in similar abundance to control plots. Thus, as for the previous experiment, we used an ANCOVA with limpets counted in the small quadrats at the last time period as a covariate and block as a random factor. Counts of barnacles and limpets were square-root transformed to meet assumptions of normality.

Effects of Chthamalus proteus on Siphonaria normalis. To examine the effects of the presence of Chthamalus proteus on the abundance of Siphonaria normalis, we set up a barnacle removal experiment on 7 cement blocks in the intertidal zone on Coconut Island. Barnacles were highly abundant on these blocks, at nearly $90 \%$ cover. On each block, we established three $5 \times 10 \mathrm{~cm}$ plots (marked with a small patch of marine epoxy in the upper right and lower left corners) which were randomly assigned to one of 3 treatments: (1) continual removal, (2) one-time removal, and (3) unmanipulated. The continual-removal and one-time removal plots were cleared of all individuals of C. proteus on May 4, 2004. Barnacle recruits were cleared from the continual-removal plots bi-weekly during low tide for $12 \mathrm{wk}$, but were allowed to recruit into the onetime removal plots. No barnacles were removed from the unmanipulated plots. The number of limpets in each plot at the beginning of the experiment was subtracted from the final number to calculate net gains or losses. These data were analyzed using ANOVA with treatment type as a fixed factor and cement block as a random factor.

Generality of pattern. To determine whether barnacles and Siphonaria normalis were negatively correlated elsewhere and to examine distribution patterns at larger scales, 3 additional intertidal sites on Oahu were surveyed in the summer of 2002. Sites were selected based on: (1) preliminary surveys that indicated barnacles and limpets were present in sufficient numbers for statistical analysis, and (2) the presence of a relatively flat surface so that differences in habitat complexity would not be a confounding factor among sites. Barnacles and S. normalis were counted in $1510 \times 10 \mathrm{~cm}^{2}$ quadrats randomly placed along $10 \mathrm{~m}$ transects in the middle of the barnacle zone at each site. During surveys, the native barnacle Nesochthamalus intertextus, when present, was recorded along with Chthamalus proteus. At Diamond Head Beach Park, patches of different substrata types (limestone and basalt) are present over scales of tens of meters at the same tidal height and shoreline aspect. Here, we surveyed 2 transects, one along a limestone segment and one along a basalt segment. At the other sites, substrata were of uniform type, and single transects were surveyed. For comparison with these sites, the survey data from the Coconut Island seawall were standardized to number of individuals per $100 \mathrm{~cm}^{2}$. All data were log transformed, and Pearson correlations were calculated for the relationship between barnacles and limpets at each site. 


\section{RESULTS}

\section{Coconut Island seawall survey}

The barnacle was found in highest abundance on dark rock and was negatively correlated with the limpet across all substratum types (Table 1). The limpet was found in highest abundance on lightcolored rock; the effect of color was statistically significant when taken alone, but not when the covariate (barnacles) was included in the model (Table 1).

\section{Recruitment preferences}

Barnacles recruited in highest numbers on rough tiles, with an apparent trend toward higher recruitment on dark, rough tiles (Fig. 1A). Rugosity was the only statistically significant factor in the recruitment of barnacles (Table 2). Limpets recruited in highest numbers to the light rough substratum (Fig. 1B); the interaction between color and rugosity was a significant factor in limpet recruitment (Table 2).

\section{Effects of Siphonaria normalis on recruitment of Chthamalus proteus}

\section{Cages}

At the end of this experiment, the caged plates with lower numbers of limpets were visibly different from the plates with higher numbers. There were more filamentous (mostly Enteromorpha sp.) and encrusting algae (mostly Ralfsia sp. and unidentified algal coralline crusts) on the plates with few limpets, and sediment was trapped by these algae. Limpet-inclusion plates were mostly free from algae and sediment.
Table 1. ANOVA for barnacle and limpet abundance vs. color, rugosity, and number of limpets or barnacles on seawall. ${ }^{*} \mathrm{p} \leq 0.05$

\begin{tabular}{|lllll|}
\hline Source & df & MS & $F$ & $\mathrm{p}$ \\
\hline Barnacle abundance & & & & \\
$\quad$ Color (C) & 1 & 1.4809 & 5.69 & $0.021^{*}$ \\
$\quad$ Rugosity (R) & 1 & 0.0184 & 0.10 & 0.758 \\
Limpets (L) & 1 & 0.0514 & 5.46 & $0.024^{*}$ \\
$\mathrm{C} \times \mathrm{R}$ & 1 & 0.1641 & 0.85 & 0.361 \\
$\mathrm{C} \times \mathrm{L}$ & 1 & 0.3003 & 1.56 & 0.218 \\
$\mathrm{R} \times \mathrm{L}$ & 1 & 0.0893 & 0.46 & 0.499 \\
$\mathrm{C} \times \mathrm{R} \times \mathrm{L}$ & 1 & 0.1187 & 0.62 & 0.437 \\
Error & 46 & 8.6686 & & \\
Total & 52 & & & \\
Limpet abundance & & & & \\
Color & 1 & 0.03040 & 0.62 & 0.435 \\
Rugosity & 1 & 0.00005 & 0.00 & 0.976 \\
Barnacles (B) & 1 & 0.32530 & 6.64 & $0.013^{*}$ \\
C $\times \mathrm{R}$ & 1 & 0.00235 & 0.05 & 0.828 \\
$\mathrm{C} \times \mathrm{B}$ & 1 & 0.4713 & 2.08 & 0.156 \\
$\mathrm{R} \times \mathrm{B}$ & 1 & 0.10187 & 0.46 & 0.501 \\
$\mathrm{C} \times \mathrm{R} \times \mathrm{B}$ & 1 & 0.02830 & 0.58 & 0.41 \\
Error & 46 & 0.02259 & & \\
Total & 52 & & & \\
\hline
\end{tabular}

Limpet incursion onto what were intended to be exclusion cages did not occur evenly across tile types. Incidental limpet recruitment was higher on the light rough tiles, and consequently those tiles had fewer algae and less sediment than the other 'exclusion' tile types. Cover of encrusting algae was greatest on the smooth plates. On the rough plates, low-lying areas had greater algal cover than higher ridges.

The interaction between rugosity and the number of Siphonaria normalis suggests that the effects of limpets were not the same on smooth and rough tiles (Table 3). Limpets had a positive effect on barnacle recruitment on smooth tiles and little effect on rough tiles (Fig. 2).
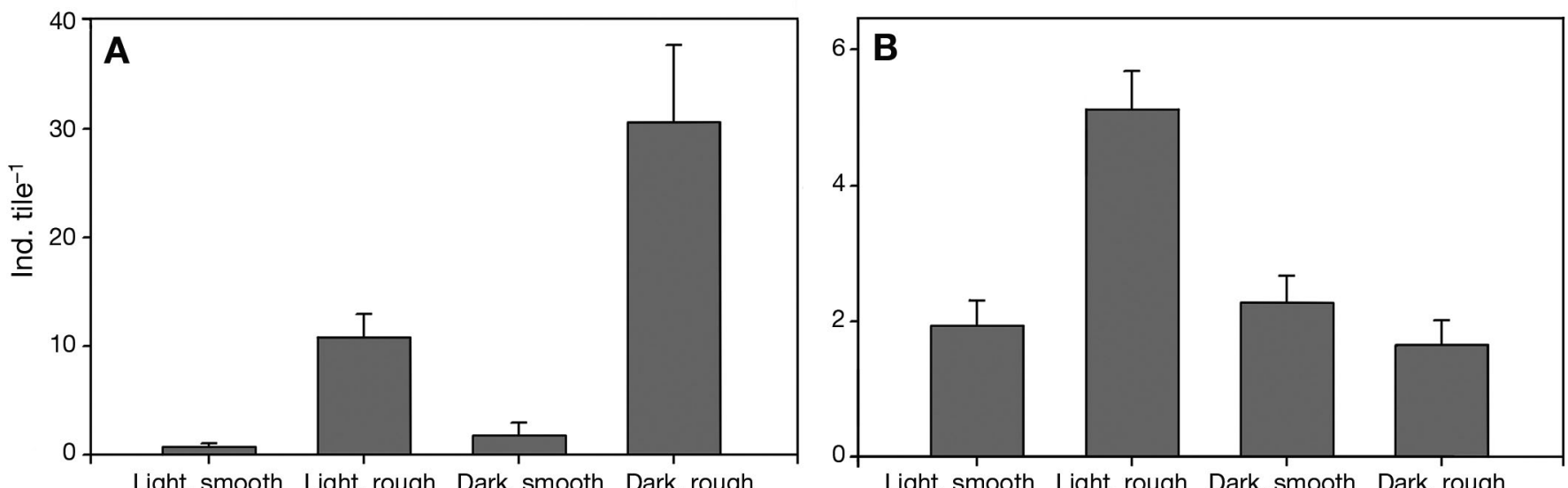

Fig. 1. Chthamalus proteus and Siphonaria normalis. Mean number of (A) invasive barnacles and (B) native limpets recruiting to different tile types (note different scales on $y$-axes). Bars: SE 
While there was a trend toward higher recruitment of barnacles to black rough tiles in limpet inclusion treatments and on light rough tiles in limpet exclusion treatments for 3 of 4 blocks, on block 3 (the overturned block) recruitment was highest on the dark smooth substratum in the inclusion treatment and about equal on the dark rough and light rough tiles in the exclusion treatment.

\section{Barriers}

At the end of the experiment, the seawall had a greenish cast in the limpet inclusion areas due to the presence of a cyanobacterial mat; in the limpet exclusion areas it was brown due to the presence of diatoms. There was no macroalgal growth. Recruitment of Chthamalus proteus was positively affected by the presence of Siphonaria normalis. No other factors were significant (Table 4 ).

\section{Effect of Chthamalus proteus on Siphonaria normalis}

All of the plots gained Siphonaria normalis over the period of the experiment. The greatest increases were in plots continually cleared of barnacles, with intermediate gains in plots that were cleared once (Fig. 3). The differences across the 3 treatments were statistically significant (Table 5).

Table 2. ANOVA for barnacle and limpet recruitment vs. tile type and number of limpets or barnacles. ${ }^{*} \mathrm{p} \leq 0.05$

\begin{tabular}{|lrccc|}
\hline Source & df & MS & $F$ & $p$ \\
\hline Barnacle recruitment & & & & \\
$\quad$ Limpets (L) & 1 & 0.0769 & 0.42 & 0.517 \\
Color (C) & 1 & 0.0941 & 0.52 & 0.474 \\
Rugosity (R) & 1 & 0.9368 & 5.16 & $0.027^{*}$ \\
$\mathrm{C} \times \mathrm{R}$ & 1 & 0.0164 & 0.09 & 0.765 \\
$\mathrm{~L} \times \mathrm{C}$ & 1 & 0.0116 & 0.06 & 0.801 \\
$\mathrm{~L} \times \mathrm{R}$ & 1 & 0.3733 & 2.06 & 0.156 \\
$\mathrm{~L} \times \mathrm{R} \times \mathrm{C}$ & 1 & 0.2690 & 1.48 & 0.228 \\
Error & 63 & 0.1815 & & \\
Total & 70 & & & \\
Limpet recruitment & & & & \\
Barnacles (B) & 1 & 0.00043 & 0.01 & 0.934 \\
Color & 1 & 0.23855 & 3.88 & 0.053 \\
Rugosity & 1 & 0.00009 & 0.00 & 0.970 \\
$\mathrm{C} \times \mathrm{R}$ & 1 & 0.49979 & 8.13 & $0.006 *$ \\
$\mathrm{~B} \times \mathrm{C}$ & 1 & 0.01456 & 0.24 & 0.628 \\
Ba $\times \mathrm{R}$ & 1 & 0.06249 & 1.02 & 0.317 \\
$\mathrm{~B} \times \mathrm{R} \times \mathrm{C}$ & 1 & 0.07369 & 1.20 & 0.278 \\
Error & 63 & 0.06144 & & \\
Total & 70 & & & \\
\hline
\end{tabular}

Table 3. ANOVA for barnacle recruitment vs. tile type and number of limpets, in exclusion cages. ${ }^{*} \mathrm{p} \leq 0.05$

\begin{tabular}{|lccrc|}
\hline Source & df & MS & \multicolumn{1}{c|}{$F$} & $\mathrm{p}$ \\
\hline Limpets (L) & 1 & 0.8197 & 5.93 & $0.027^{*}$ \\
Color (C) & 1 & 0.2221 & 1.61 & 0.223 \\
Rugosity (R) & 1 & 3.1724 & 22.95 & $<0.0005^{*}$ \\
$\mathrm{~L} \times \mathrm{C}$ & 1 & 0.1199 & 0.87 & 0.366 \\
$\mathrm{~L} \times \mathrm{R}$ & 1 & 1.7845 & 12.91 & $0.002^{*}$ \\
$\mathrm{C} \times \mathrm{R}$ & 1 & 0.0679 & 0.49 & 0.493 \\
$\mathrm{~L} \times \mathrm{C} \times \mathrm{R}$ & 1 & 0.0039 & 0.03 & 0.869 \\
Error & 16 & 0.1382 & & \\
Total & 23 & & & \\
\hline
\end{tabular}

\section{Generality of pattern}

Only one barnacle was found on the limestone transect at Diamond Head, indicating the importance of substrate type, but precluding a statistical analysis of the relationship between barnacles and limpets along that transect.

The relationship between barnacle and limpet densities was examined for the basalt transect at Diamond Head and the surveys of the cement seawalls at Waikiki and Kualoa (without substratum as a factor). For comparison, the relationship between barnacles and limpets on the Coconut Island seawall was examined similarly.

The means and ranges of limpets in quadrats varied between sites, with Coconut Island having 3 to 12 times as many limpets on average as the other sites (Table 6). Sites were more similar in mean numbers of barnacles, but Coconut Island had the widest range, with up to 3 times more barnacles than the other sites. There was a positive correlation at Waikiki, and a negative correlation at Coconut Island (Table 6, Fig. 4). However, there was no correlation between barnacle and limpet abundances at Kualoa or along the basalt transect at Diamond Head.

At Diamond Head, the mean density of limpets along the limestone transect (6.3 per quadrat) was similar to that along the basalt transect (6.0), but the mean number of barnacles per quadrat was much lower on the limestone (0.07) than on the basalt (37.0). Barnacles were present along the limestone shore in the few places where fragments of dark rock were embedded in limestone (authors' pers. obs.).

\section{DISCUSSION}

\section{Experiments}

The experimental work indicated that both substratum and biotic interactions were important in deter- 


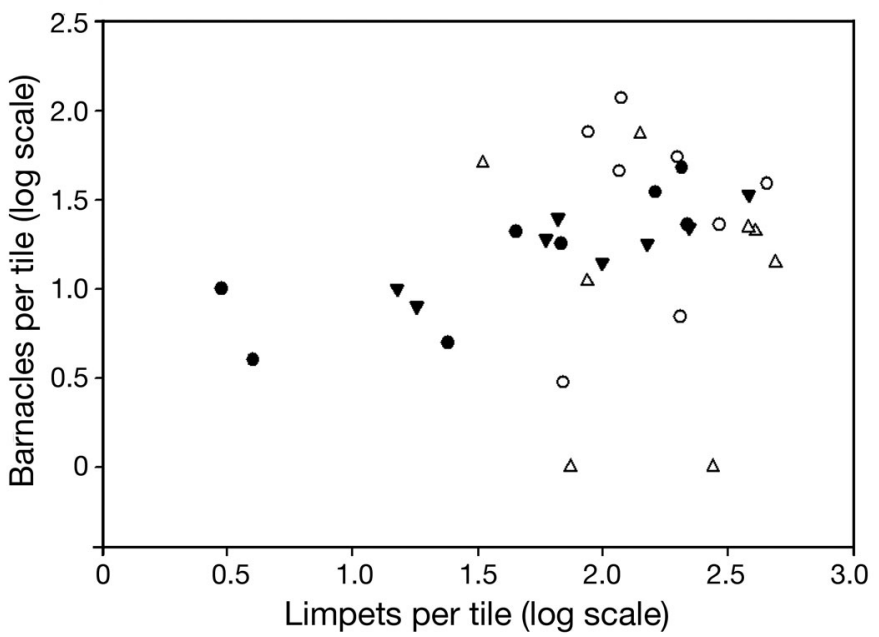

Fig. 2. Chthamalus proteus and Siphonaria normalis. Plot (log scale) of limpets vs. barnacles across each of 4 tile types in the cage experiment. $(\triangle)$ Dark rough tiles; $(\bigcirc)$ light rough tiles; $(\nabla)$ dark smooth tiles; $(\bullet)$ light smooth tiles

mining the abundance of Siphonaria normalis and Chthamalus proteus at Coconut Island. C. proteus recruited preferentially to rough substrata, with a trend toward more recruitment on dark substrata. $S$. normalis preferred light-colored, rough substrata.

While Siphonaria normalis did not appear to affect recruitment of Chthamalus proteus when the limpet was present in low densities (the recruitment preference experiments), there was a positive effect on the barnacle's recruitment when the limpet was present in higher densities, particularly on smooth surfaces (cage and barrier experiments). If this positive relationship is the result of the grazing activities of $S$. normalis, it makes sense that this would be important only above some threshold level of limpet abundance.

Similarly, Chthamalus proteus did not affect limpets in the recruitment preference experiments, where it was present in low densities. However, the barnacle did negatively impact Siphonaria normalis in the removal experiments on the blocks, where barnacle cover was extremely high, perhaps by creating suboptimal grazing conditions that resulted in limpets moving to patches with lower numbers of barnacles.

Taken together, these experiments suggest that Siphonaria normalis had a positive effect on Chthamalus proteus, while the barnacle had a negative effect on the limpet. Both of these effects appeared to be density dependent in that they became more prevalent at higher densities of organisms.

\section{Surveys}

The generality of our experiments conducted at Coconut Island was examined through surveys of addi-

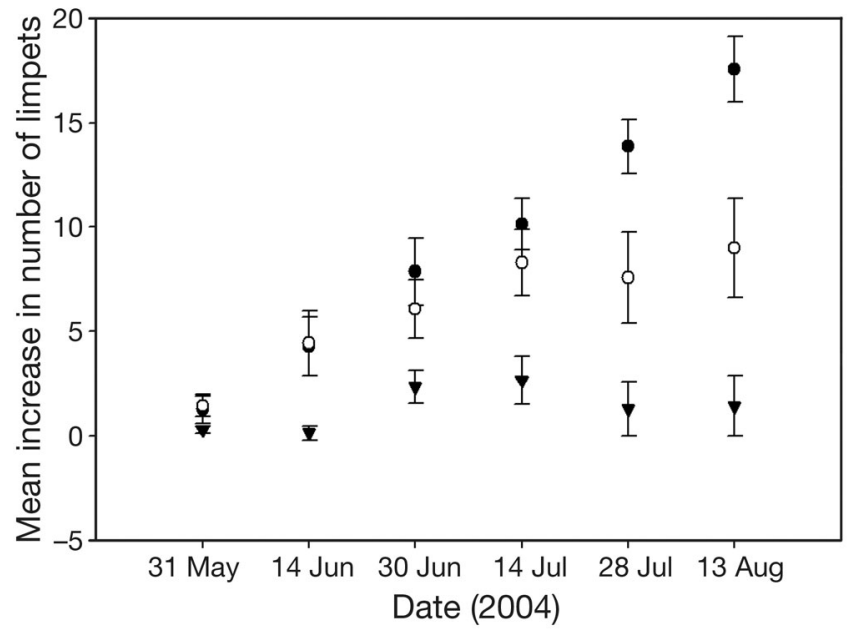

Fig. 3. Siphonaria normalis. Mean number of limpets on 3 types of plots in the barnacle-removal experiment across six $2 \mathrm{wk}$ periods. Bars: $\pm \mathrm{SD}_{i}(\bullet)$ continual-removal plots; $(\bigcirc)$ one-time removal plots; $(\boldsymbol{\nabla})$ unmanipulated plots

Table 4. ANOVA for barnacle recruitment on seawall vs. number of limpets, barrier experiment. ${ }^{*} \mathrm{p} \leq 0.05$

\begin{tabular}{|lrrcc|}
\hline Source & df & MS & $F$ & $\mathrm{p}$ \\
\hline Plot (P) & 3 & 1.574 & 0.79 & 0.510 \\
Limpets (L) & 1 & 17.566 & 8.79 & $0.006^{*}$ \\
P $\times$ L & 3 & 2.292 & 1.15 & 0.345 \\
Error & 32 & 1.998 & & \\
Total & 39 & & & \\
\hline
\end{tabular}

Table 5. ANOVA table for limpet abundance on barnacleremoval plots, final time point. ${ }^{*} \mathrm{p} \leq 0.05$

\begin{tabular}{|lrrrc|}
\hline Source & df & \multicolumn{1}{c|}{ MS } & \multicolumn{1}{c|}{$F$} & \multicolumn{1}{c|}{$\mathrm{p}$} \\
\hline Block & 6 & 29.11 & 2.42 & 0.0918 \\
Treatment & 2 & 333.90 & 27.79 & $<0.0005^{*}$ \\
Error & 12 & 12.02 & & \\
Total & 20 & & & \\
\hline
\end{tabular}

Table 6. Chthamalus proteus and Siphonaria normalis. Range (mean) of barnacle and limpet densities per $100 \mathrm{~cm}^{2}$, and correlation between barnacles and limpets at 4 intertidal sites. ${ }^{*} \mathrm{p} \leq 0.05$

\begin{tabular}{|llcrc|}
\hline Site & Limpets & Barnacles & $\mathrm{R}$ & $\mathrm{p}$ \\
\hline Diamond Hd. & $1-11(6)$ & $0-145(37)$ & 0.31 & 0.266 \\
Kualoa & $0-7(3)$ & $3-174(66)$ & 0.13 & 0.598 \\
Waikiki & $2-21(12)$ & $0-142(83)$ & 0.48 & $0.007^{*}$ \\
Coconut Isl. & $0-112(36)$ & $0-476(57)$ & -0.59 & $0.001^{*}$ \\
\hline
\end{tabular}


tional sites. If the experimentally determined mechanisms underlying interactions between the invasive Chthamalus proteus and native Siphonaria normalis at Coconut Island are occurring at other locations in Hawaii, one would expect to find a pattern of little or no correlation between barnacles and limpets at sites where either organism is present in low abundance, a positive correlation where both are present in intermediate abundance (at these densities limpets are expected to facilitate barnacles, but not be negatively impacted by them), and a negative correlation where barnacles are highly abundant. Although not demonstrated in the experiments, it is also possible that, at very high densities, $S$. normalis might negatively impact $C$. proteus through the reduction of settlement space for the barnacle. Siphonariids have not been reported 'bulldozing' or ingesting barnacle settlers.

The surveys showed the predicted pattern: no correlation between barnacles and Siphonaria normalis at Diamond Head and Kualoa (the sites with the lowest densities); a positive correlation between barnacles and limpets at Waikiki (the site with intermediate densities of both organisms); and a negative association between barnacles and $S$. normalis at Coconut Island (the site with the highest numbers of both organisms).

It is not clear what drives the differences in densities of these 2 species at the different sites. However, it is likely that barnacle larvae are retained in Kaneohe Bay and that larval supply is limited at the other sites (Zabin 2005). Other factors, including water flow, predators and other space competitors, and differences in smallscale hydrodynamics and micro-climates at a site are

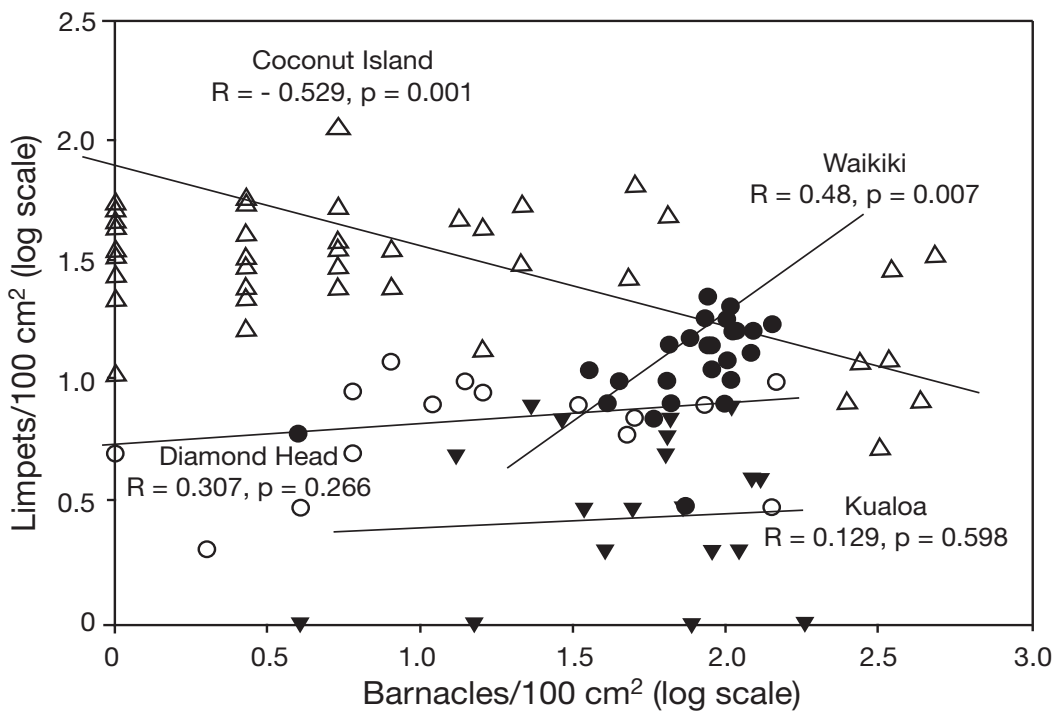

Fig. 4. Chthamalus proteus and Siphonaria normalis. Correlations between barnacle and limpet densities at 4 sites. Barnacles and limpets were counted in 52 quadrats at Coconut Island; 50 at Waikiki, 15 at Diamond Head and 20 at Kualoa. $(\triangle)$ Coconut Island; ( $)$ Waikiki; (O) Diamond Headi $_{(\boldsymbol{\nabla}) \text { Kualoa }}$ also likely to affect the abundance and distribution of Chthamalus proteus and Siphonaria normalis. Despite these other potentially important factors, the patterns seen here suggest that these species interact and influence each other at sites other than Coconut Island.

At Coconut Island, survey and experimental data showed that barnacle abundance was also influenced by the presence of dark-colored substrata, and this added to the strong negative association between barnacles and limpets. While experiments indicated that Siphonaria normalis has a preference for light-colored substrata, this appears to be secondary to the presence of barnacles as a cause of the pattern of limpet abundance. At the larger scale of the surveys at Diamond Head, substratum preferences were not evident for $S$. normalis (equal densities on basalt and limestone), but were for barnacles (higher abundance on the basalt rock).

\section{Predictability}

How well could the interactions between Chthamalus proteus and Siphonaria normalis have been predicted based on knowledge about similar organisms elsewhere? It is well established that barnacles prefer to settle on rough surfaces (Crisp \& Barnes 1954, Crisp 1961, 1974, Chabot \& Bourget 1988). Some barnacle species have been observed to settle preferentially on dark substratum (Edmondson \& Ingram 1939, Pomerat \& Reiner 1942, McDougall 1943, Smith 1948, but see Barnes et al. 1951, Luckens 1970) and the absence of tropical barnacles from coral rock, which is generally light-colored, has been reported by Southward \& Newman (1977). Coral rock is highly porous, and it has been suggested that barnacles, especially those with wholly or partially membranous bases, like Chthamalus proteus and Nesochthamalus intertextus, would be more subject to desiccation than those with calcified bases (Southward \& Newman 1977). Many other light-colored substrata, such as sandstone, weather easily and may not be good settlement sites for this reason.

Observations of substrate preferences have not been made previously for Siphonaria normalis. Vermeij (1971b) found that body temperatures of $S$. normalis were generally higher than substratum temperatures and were higher on basalt than on limestone, but whether these differences are enough to result in differential survival on the 2 types of substrata is unknown. The light-colored tiles remained 0.5 to $1^{\circ} \mathrm{C}$ cooler than the dark tiles during a spring 
afternoon at Coconut Island and cooled more quickly (authors' unpubl. data), and higher temperatures can be expected in summer. It is possible that the limpets, particularly juveniles, which might be more susceptible to heat stress and desiccation, survive better on light-colored substrata. On a wave-washed bench like that at Diamond Head, this might be less of a factor than at a wave-protected site like Coconut Island.

Siphonariid limpets (subclass Pulmonata) have weaker radulae than those in the subclass Prosobranchia (families Patellidae and Fissurellidae) and tend to crop rather than completely remove the algae on which they graze (Hodgson 1999). As a result, in some intertidal locations, their feeding activities appear to have little impact on algae (Underwood \& Jernakoff 1981, Black et al. 1988). Nevertheless, grazing by siphonariids can be important in structuring macro- and microalgal communities (Jara \& Moreno 1984, Levings \& Garrity 1984, Iwasaki 1993a,b, Kim 1997), and thus might affect other organisms that interact with algae. The impact of siphonariid grazing on barnacle recruitment and survival is negative in at least one case (Levings \& Garrity 1984), and positive in several others (Bastida et al. 1971, Iwasaki 1993a,b). The effects of siphonariid limpets on barnacles are thus not predictable across different sets of organisms and locations.

Barnacles have negative impacts on siphonariid abundance in other locations. In Florida, Siphonaria species are most abundant at tidal heights above and below the highest densities of 3 barnacle species (Voss 1959); this spatial arrangement was deemed to be the result of competition for space, although the author did not confirm this experimentally. S. gigas was less abundant following a heavy recruitment of Chthamalus fissus in Costa Rica (Sutherland \& Ortega 1986).

Similar to our findings, other studies have found an initially positive association between limpets and barnacles shifting to negative as densities of barnacles increased. In the Sea of Cortez, settlement of the barnacle Chthamalus anisopoma was facilitated by the grazing activities of the limpet Collisella strongiana, but the limpet subsequently disappeared when high numbers of the barnacle recruited (Dungan 1986). In the Mediterranean, Benedetti-Cecchi (2000) reported positive effects of limpet grazing (Patella spp.) on recruitment of Chthamalus spp. and subsequent negative effects of Chthamalus on Patella spp. after the barnacles had settled in high numbers. On the Isle of Man, Hawkins and Hartnoll (1982) found highest numbers of recruits of $P$. vulgata at intermediate levels of abundance of the barnacle Semibalanus balanoides $(50 \%$ cover as opposed to 100 or $2 \%$ ) and highest limpet mortality where barnacle cover was $100 \%$.

Earlier in the history of the Chthamalus proteus invasion of Hawaii, the impacts of this barnacle on native species were predicted to be minimal, as the intertidal zone in Hawaii is generally characterized as being 'barren' (Southward et al. 1998, Coles \& Eldredge 2002), thus precluding competition between invertebrate species via space limitation. This prediction was too broad. While cover of sessile organisms is low in the high to mid-intertidal zone at many wave-exposed sites, cover can be relatively high in low-energy sites, such as Kaneohe Bay, harbors and lagoons (authors' pers. obs.). Based on the studies mentioned in the previous paragraph, a prediction might have been made that, in Hawaii, C. proteus would negatively impact Siphonaria normalis in locations where the barnacle is present in high abundance.

As dense patches of barnacles are rare in most intertidal locations in Hawaii, the invasion of Chthamalus proteus represents a novel circumstance for the native pulmonate limpet. In the barnacle removal experiment, the absence of barnacles resulted in an increase in the numbers of both new limpet recruits and larger adults. This implies that Siphonaria normalis is more successful in barnacle-free areas. Limpets grew more slowly in the presence of barnacles, probably due, at least in part, to limited grazing space, but this did not measurably increase mortality (Lewis \& Bowman 1975, Branch 1976, Choat 1977, Hawkins \& Hartnoll 1982, Sutherland \& Ortega 1986, Crisp et al. 1990). Size depression also likely leads to lowered fecundity in limpets, particularly at extremely high levels of barnacle cover (Branch 1976). If the crawl-away juveniles of $S$. normalis do not disperse very far, over time it might be expected that densities of $S$. normalis would decrease in locations with high densities of $C$. proteus such as Kaneohe Bay, assuming other factors such as disturbance and predation do not eventually lower barnacle cover.

\section{CONCLUSIONS}

The nature of interactions between barnacles and limpets (positive or negative) can depend on size, life history stage, the nature of grazing activities by the limpets, the intensity of predation, variations in recruitment intensity and in density of adults, and a host of abiotic factors (e.g. Branch 1976, Hawkins \& Hartnoll 1982, Underwood et al. 1983, Dungan 1986, Wootton 1993). In Hawaii, the native pulmonate limpet Siphonaria normalis can facilitate the establishment of the competitively dominant invasive barnacle Chthamalus proteus. Since the strength of that interaction is density dependent, and substratum type affects the density of recruits of both species, coexistence of the 2 species appears to be promoted at various scales (within site and between sites), due to substratum heterogeneity. 
Acknowledgements. We thank B. Forman, V. Fread, S. Pang and A. Parsa for assistance with fieldwork, A. D. Taylor for assistance with experimental design and analysis, J. E. Smith for help with algae identification, and the Hawaii Institute of Marine Biology for allowing us to set up experiments on Coconut Island. This work was funded in part by a National Science Foundation (NSF) Graduate Research Fellowship, an NSF Graduate Teaching Fellowship in K-12 Education and the Edmondson Research Fund to C.J.Z. This paper is funded in part by a grant to Michael G. Hadfield from the National Oceanic and Atmospheric Administration, Project \#R/AN-1, which is sponsored by the University of Hawaii Sea Grant College Program, SOEST, under Institutional Grant No. NA86RG0041 from NOAA Office of Sea Grant, Department of Commerce. The views expressed herein are those of the author(s) and do not necessarily reflect the views of NOAA or any of its subagencies. UNIHI-SEAGRANT-JC-00-42.

\section{LITERATURE CITED}

Barnes H, Crisp DJ, Powell HT (1951) Observations on the orientation of some species of barnacles. J Anim Ecol 20: 227-241

Bastida R, Capezzani A, Torti MR (1971) Fouling organisms in the port of Mar del Plata (Argentina). I. Siphonaria lessoni: ecological and biometric aspects. Mar Biol 10:297-307

Benedetti-Cecchi L (2000) Predicting direct and indirect interactions during succession in a mid-littoral rocky shore assemblage. Ecol Monogr 70:45-72

Black R, Lymbery A, Hill A (1988) Form and function: size of radular teeth and inorganic content of faeces in a guild of grazing molluscs at Rottnest Island, Western Australia. J Exp Mar Biol Ecol 121:23-35

Branch GM (1976) Interspecific competition experienced by South African Patella species. J Anim Ecol 45:507-529

Branch GM, Eekhout S, Bosman AL (1990) Short-term effects of the 1988 Orange River floods on the intertidal rockyshore communities of the open coast. Trans R Soc S Africa 47:331-354

Carlton JT (1999) The scale and ecological consequences of biological invasions in the world's oceans. In: Sandlund OT, Schei PJ, Viken A (eds) Invasive species and biodiversity management. Kluwer, Dordrecht, p 195-212

Chabot R, Bourget E (1988) Influence of substratum heterogeneity and settled barnacle density on the settlement of cypris larvae. Mar Biol 97:45-56

Choat JH (1977) The influence of sessile organisms on the population biology of three species of acmaeid limpets. J Exp Mar Biol Ecol 26:1-26

Coles SL, Eldredge LG (2002) Nonindigenous species introductions on coral reefs: a need for information. Pac Sci 56: 191-209

Cook SB (1969) Experiments on homing in the limpet Siphonaria normalis. Anim Behav 17:679-682

Cook SB, Cook CB (1978) Tidal amplitude and activity in the pulmonate limpets Siphonaria normalis (Gould) and $S$. alternata (Say). J Exp Mar Biol Ecol 35:119-136

Creese RG (1982) Distribution and abundance of the acmaeid limpet, Patelloida latistrigata, and its interaction with barnacles. Oecologia 52:85-96

Creese RG, Underwood AJ (1982) Analysis of inter- and intraspecific competition amongst intertidal limpets with different methods of feeding. Oecologia 53:337-346

Crisp DJ (1961) Territorial behavior in barnacle settlement. J Exp Mar Biol Ecol 38:429-446

Crisp DJ (1974) Factors influencing the settlement of marine invertebrate larvae. In: Grant PT, Mackie, AM (eds) Chemoreception in marine organisms. Academic Press, New York, p 177-265

Crisp DJ, Barnes H (1954) The orientation and distribution of barnacles at settlement with particular reference to surface contour. J Anim Ecol 23:142-162

Crisp DJ, Wieghell JG, Richardson CA (1990) Tidal microgrowth bands in Siphonaria gigas (Gastropoda, Pulmonata) from the coast of Costa Rica. Malacologia 31: $229-236$

Dando PR, Southward AJ (1980) A new species of Chthamalus (Crustacea: Cirripedia) characterized by enzyme electrophoresis and shell morphology: with a revision of other species of Chthamalus from the western shores of the Atlantic Ocean. J Mar Biol Assoc UK 60:787-831

Dungan ML (1986) Three-way interactions: barnacles, limpets, and algae in a Sonoran Desert rocky intertidal zone. Am Nat 127:292-316

Edmondson $\mathrm{CH}$, Ingram WM (1939) Fouling organisms in Hawaii. Occas Pap Bernice P Bishop Mus 14:251-300

Grosholz ED (2002) Ecological and evolutionary consequences of coastal invasions. Trends Ecol Evol 17:22-27

Hawkins SJ, Hartnoll RG (1982) The influence of barnacle cover on the numbers, growth and behaviour of Patella vulgata on a vertical pier. J Mar Biol Assoc UK 62: 855-867

Hodgson AN (1999) The biology of siphonariid limpets (Gastropoda: Pulmonata). Oceanogr Mar Biol Annu Rev 37: 245-314

Iwasaki K (1993a) Individual variation, social structure, community organization and hierarchical views in the marine context. In: Kawanabe $\mathrm{H}$, Cohen JE, Iwasaki K (eds) Mutualism and community organization: behavioral, theoretical and food-web approaches. Oxford University Press, Oxford, p 13-36

Iwasaki K (1993b) Synergistic effects of mixed grazing by intertidal limpets on sessile organisms: consequences of differences in grazing ability and feeding habit. Physiol Ecol Jap 30:1-30

Jara FH, Moreno CA (1984) Herbivory and structure in a midlittoral rocky community: a case in southern Chile. Ecology 65:28-38

Kay EA (1979) Hawaiian marine shells, Vol 4: Mollusca. Bishop Museum Press, Honolulu, HI

Kim JH (1997) The role of herbivory, and direct and indirect interactions, in algal succession. J Exp Mar Biol Ecol 217: 119-135

Levings SC, Garrity SD (1984) Grazing patterns in Siphonaria gigas (Mollusca, Pulmonata) on the rocky Pacific coast of Panama. Oecologia 64:152-159

Lewis JR, Bowman RS (1975) Local habitat-induced variations in the population dynamics of Patella vulgata L. J Exp Mar Biol Ecol 17:165-203

Luckens PA (1970) Breeding, settlement and survival of barnacles at artificially modified shore levels at Leigh, New Zealand. NZ J Mar Freshw Res 4:497-515

Matsuda C (1973) A shoreline survey of free-living intertidal barnacles (Class Crustacea; Subclass Cirripedia; Order Thoracica) on the island of Oahu, Hawaii. Master's thesis, University of Hawaii, Manoa

McDougall KD (1943) Sessile marine invertebrates of Beaufort, North Carolina: a study of settlement, growth and seasonal fluctuations among pile-dwelling organisms. Ecol Monogr 13:321-374

Miller KM, Carefoot TH (1989) The role of spatial and size refuges in the interaction between juvenile barnacles and grazing limpets. J Exp Mar Biol Ecol 134:157-174 
Pomerat CM, Reiner ER (1942) The influence of surface angle and of light on the attachment of barnacles and other sedentary organisms. Biol Bull 82:14-25

Raimondi PT (1988) Rock type affects settlement, recruitment, and zonation of the barnacle Chthamalus anisopoma Pilsbry. J Exp Mar Biol Ecol 123:253-267

Smith FGW (1948) Surface illumination and barnacle attachments. Biol Bull 94:33-39

Southward AJ, Newman JA (1977) Aspects of the ecology and biogeography of the intertidal and shallow-water balanomorph cirripedia of the Caribbean and adjacent sea-areas. In: Fisheries Report, No. 200. FAO, Rome, p $407-425$

Southward AJ, Burton RS, Coles SL, Dando PR and 5 others (1998) Invasion of Hawaiian shores by an Atlantic barnacle. Mar Ecol Prog Ser 165:119-126

Stimson J (1970) Territorial behavior of the owl limpet, Lottia gigantea. Ecology 51:113-118

Sutherland JP, Ortega S (1986) Competition conditional on recruitment and temporary escape from predators on a tropical rocky shore. J Exp Mar Biol Ecol 95:155-166

Editorial responsibility: Charles Birkeland (Contributing Editor), Honolulu, Hawaii, USA
Underwood AJ, Jernakoff P (1981) Effects of interactions between algae and grazing gastropods on the structure of a low-shore intertidal algal community. Oecologia 48:221233

Underwood AJ, Denley EJ, Moran MJ (1983) Experimental analyses of the structure and dynamics of mid-shore rocky intertidal communities in New South Wales. Oecologia 56: 202-219

Vermeij GJ (1971a) Substratum relationships of some tropical Pacific intertidal gastropods. Mar Biol 10:315-320

Vermeij GJ (1971b) Temperature relationships of some tropical Pacific intertidal gastropods. Mar Biol 10:308-314

Voss NA (1959) Studies on the pulmonate gastropod Siphonaria pectinata (Linneaus) from the southeast coast of Florida. Bull Mar Sci Gulf Caribb 9:84-99

Wootton JT (1993) Indirect effects and habitat use in an intertidal community: interaction chains and interaction modification. Am Nat 141:71-89

Zabin CJ (2005) Community ecology of the invasive barnacle Chthamalus proteus in Hawaii. PhD dissertation, University of Hawaii, Manoa

Submitted: August 2, 2005; Accepted: July 7, 2006

Proofs received from author(s): April 21, 2007 